\title{
Colistin Update on Its Mechanism of Action and Resistance, Present and Future Challenges
}

\author{
Ferdinando F. Andrade 1,2,*佑, Daniela Silva ${ }^{3,4}$, Acácio Rodrigues ${ }^{1,5,6}$ and Cidália Pina-Vaz 1,5 \\ 1 Division of Microbiology, Department of Pathology, Faculty of Medicine, University of Porto, 4200-319 Porto, \\ Portugal; agr@med.up.pt (A.R.); cpinavaz@med.up.pt (C.P.-V.) \\ 2 Farmanimal Veterinary Centre, 2500-323 Caldas da Rainha, Portugal \\ 3 Clinical Microbiology Department, Porto University Hospital Center, 4099-001 Porto, Portugal; \\ daniela.sfsilva@gmail.com \\ 4 Abel Salazar Institute of Biomedical Sciences, University of Porto, 4050-313 Porto, Portugal \\ 5 CINTESIS-Center for Health Technology and Services Research, Faculty of Medicine, University of Porto, \\ 4200-319 Porto, Portugal \\ 6 Burn Unit, S. João University Hospital Center, 4200-319 Porto, Portugal \\ * Correspondence: franca.andrade@gmail.com; Tel.: +351-917283283
}

Received: 1 September 2020; Accepted: 30 October 2020; Published: 2 November 2020

check for updates

\begin{abstract}
Colistin has been extensively used since the middle of the last century in animals, particularly in swine, for the control of enteric infections. Colistin is presently considered the last line of defense against human infections caused by multidrug-resistant Gram-negative organisms such as carbapenemase-producer Enterobacterales, Acinetobacter baumanni, and Pseudomonas aeruginosa. Transferable bacterial resistance like mcr-genes was reported in isolates from both humans and animals. Researchers actively seek strategies to reduce colistin resistance. The definition of guidelines for colistin therapy in veterinary and human medicine is thus crucial. The ban of colistin use in swine as a growth promoter and for prophylactic purposes, and the implementation of sustainable measures in farm animals for the prevention of infections, would help to avoid resistance and should be encouraged. Colistin resistance in the human-animal-environment interface stresses the relevance of the One Health approach to achieve its effective control. Such measures should be addressed in a cooperative way, with efforts from multiple disciplines and with consensus among doctors, veterinary surgeons, and environment professionals. A revision of the mechanism of colistin action, resistance, animal and human use, as well as colistin susceptibility evaluation is debated here.
\end{abstract}

Keywords: colistin; polymyxin; antimicrobial resistance; multidrug-resistant gram-negative organisms

\section{Introduction}

Colistin (Polymyxin E) is a polycationic peptide antimicrobial, discovered in 1949 in Japan, produced by Bacillus polymyxa. It belongs to the polymyxin class of antibiotics, with hydrophilic and lipophilic properties. The polymyxin group includes five different chemical compounds (polymyxins A, B, C, D, and E) [1,2]; only two polymyxins are used clinically: polymyxin B and colistin, also called polymyxin E [3]. For clinical use, two forms of colistin are available: a prodrug, colistin methanesulfonate sodium (CMS), for parenteral use, and colistin sulfate (CS) for oral, inhalator, or topical use [4].

It was first used in human and veterinary medicine in 1952, but between the 1970s and 1980s, its medical use was almost abolished, thereby persisting the veterinary use. In recent years, colistin has begun to be used in humans as a last resource agent in the case of infections by multidrug-resistant Gram-negative bacilli, notably by carbapenemase-producing Enterobacterales, Pseudomonas aeruginosa, 
and Acinetobacter baumannii [5-8]. The World Health Organization (WHO) and other government agencies such as Health Canada have reclassified colistin in the category of "very high importance for Human Medicine" [9,10].

Colistin is considered by the European Medicines Agency (EMA) as antibiotics critically important in human medicine-Category B- “Restrict". This means its administration in veterinary medicine should be limited to reduce the danger to public health. Quinolones (fluoroquinolones and other quinolones), cephalosporins of either third and fourth generation (excluding those with beta-lactamase inhibitors), and polymyxins are drugs included in this category. Antibiotics in Category B should be reserved for treatment when antimicrobials in Categories $C$ or $D$ are not, from a clinical point of view, effective and there is no other alternative. In general, antibiotic utilization should rely upon the performance of an antimicrobial susceptibility test (AST), particularly those included in Category B [11].

\section{Mechanism of Action}

Colistin L-diaminobutyric acid, positively charged, binds through electrostatic interaction to the negatively charged phosphate groups of lipid A, an important component of lipopolysaccharide (LPS) of Gram-negative bacilli [12]. The lipid A plays a crucial role in bacterial permeability and exchange with cell exterior [6]. Colistin displaces the divalent cations of calcium $\left(\mathrm{Ca}^{2+}\right)$ and magnesium $\left(\mathrm{Mg}^{2+}\right)$ in a competitively way, impairing the LPS three-dimensional structure. Colistin then inserts its hydrophobic terminal acyl fat chain, causing an expansion of the external outer membrane (OM) monolayer. A permeabilization of OM occurs, allowing colistin to get through $\mathrm{OM}$ as a self-promotion. The synergy exhibited by colistin and other antimicrobials with hydrophilic properties such as b-lactamics, gentamicin, rifampicin, meropenem, and tigecycline is explained by this process [13]. The phospholipid bilayer of the inner membrane (IM), present only in Gram-negatives, loses its stability, because of the action of colistin by including hydrophilic groups in the fatty acid chains, changing its integrity and leading to its destruction, failing to maintain cellular content, leading to cell lysis [6]. Binding to lipid A, colistin also exerts an anti-endotoxin activity [1], preventing the induction of shock by endotoxin. Colistin essentially solubilizes the bacterial cell membrane, resulting in a bactericidal effect.

\section{Colistin Resistance}

Resistance to colistin can be explained by a variety of mechanisms. Until 2015, it was thought to be acquired solely via chromosomal point mutations. As LPS is the target of colistin, any change in it can change the behavior of colistin [7]. Salmonella and E. coli are able to modify LPS by changing lipid A through the biosynthesis of 4-amino-4-deoxy-L-arabinose (L-Ara4N) and/or phosphoethanolamine (PEtn). Its biosynthesis is associated with chromosomal mediated resistance, dependent on two-component response regulators and sensor kinase systems: PmrA/PmrB and PhoP/PhoQ [14-16]. The first system PmrA/PmrB also controls the pmr HIJKLM operon, which promotes the synthesis of N4-aminoarabinosis, which in turn, when bonding chemically the fractions of lipid A, changes the negative charge of the cell membrane by neutralizing the negatively charged phospholipids. This resistance mechanism is exhibited by Pseudomonas aeruginosa [17]. The resistance to colistin expressed by Acinetobacter baumannii is based on the suspension of LPS production. This absence of LPS production may result from the inactivation of a lipid A biosynthesis gene, lpxA, lpxC, or lpxD, and leads to resistance to colistin due to the absence of lipid A [18].

Regarding the resistance expressed by K. pneumoniae to polymyxins, its resistance mechanism is based on the inactivation of the $\mathrm{mgrB}$ gene and, in deregulation, the two-component regulatory systems PhoPQ and PmrAB. Inactivations in the mgrB gene were responsible for the exhibition of resistance by K. pneumonia to colistin. When the PhoP/PhoQ signaling system is activated, a small transmembrane regulatory protein, composed of 47 amino acids, is produced: the MgrB. This protein prevents the phosphorylation of PhoP, probably by suppressing the PhoQ kinase or promoting the phosphatase. As PhoP phosphorylation is found to increase the transcription of the $\mathrm{mgrB}$ gene and, on the other 
hand, MgrB inhibits this phosphorylation, then this protein is clearly a mediator of negative feedback in the PhoQ/PhoP signaling circuit $[19,20]$.

Initially reported in China in 2015 [21], and later in Asia, Africa, Europe, and America [22-25], a plasmid mediated colistin resistance, $m c r-1$ gene, was described in Escherichia coli. The mcr-1 is an enzyme that changes lipid A present in LPS with a metabolite of phosphoethanolamine, suppressing its binding to colistin.

The chances of transferring bacterial resistance to colistin along with resistance to broad-spectrum cephalosporin are significantly raised by the fact that a single plasmid can co-harbor mcr-1 together with the extended-spectrum beta-lactamase gene (ESBL). This poses huge challenges when treating infections with Gram-negative etiology. A mcr-1 gene located chromosomally was detected in two colistin-resistant E. coli isolates, collected from calves [26].

Later, in Belgium, a new colistin resistance gene, $m c r-2$, was also discovered, carried by a plasmid in E. coli isolates from porcine and bovine biologic samples and also co-harboring ESBL genes [27].

Interestingly, the coexistence of several mcr genes on E. coli does not necessarily mean a significant difference in terms of minimum inhibitory concentration (MIC), compared with resistant isolates of Salmonella only carrying the single plasmid $m c r-1$ gene [28]. The $m c r-1$ gene found in resistant Enterobacterale isolated from swine was often associated to a low level of resistance; MICs of 4 or $8 \mathrm{mg}$ /L were reported for most isolates, which are only 2-4 times higher than the European Committee on Antimicrobial Susceptibility Testing (EUCAST) clinical breakpoint $(2 \mathrm{mg} / \mathrm{L})[21,28,29]$ or Clinical Laboratory Standard Institute (CLSI). Strains with minimal inhibitory concentrations inferior to $2 \mathrm{mg} / \mathrm{L}$ are considered susceptible by EUCAST protocol and intermediate by CLSI; susceptible category was recently eliminated by CLSI.

Colistin resistant bacteria also share resistance to other types of antibiotics used such as aminoglycosids; tetracycline; sulfonamide and trimethoprim; lincosamide; b-lactamics; quinolones; and third generation cephalosporins involving different mechanisms of resistance such as enzymatic, efflux, impermeability, or point mutations [29-33].

Meanwhile, seven additional $m c r$ homologues $(m c r-3$ to $m c r-9)$ have been identified in Enterobacterales [34,35] and PCR tests have been developed to enable their detection [36]. This mechanism of resistance can be acquired during therapy and easily transmitted, increasing the spread of resistance.

The emergence of resistance to colistin, one of the few remaining therapeutical alternatives for patients infected with K. pneumoniae resistant to carbapenems and other important antimicrobial groups, is thus a major concern, notably among humans.

\section{Epidemiology of Colistin-Resistance}

According to the European Centre for Disease Prevention and Control (ECDC), in 2017, isolates resistant to colistin represented $8.5 \%$ (2.4\% of all reported K. pneumonia isolates and only sporadically on E coli). Greece and Italy were the countries responsible for the vast majority $(88.5 \%)$ of these reports [37].

On the other hand, the same data source reported in 2016 that only $51.3 \%$ of all P. aeruginosa isolates were colistin susceptible. Concerning Acinetobacter spp., colistin susceptibility data reach up to $51.3 \%$ of all isolates [37].

However, the ECDC in 2018 repeated the warnings that these findings may not be representative for Europe as a whole and should be interpreted with caution because of the low number of isolates tested, the relatively high proportion of isolates from areas of high resistance, and the technical complexities involving colistin susceptibility tests [38]. The possibility of transmission of colistin resistant $E$. coli between species is possible, particularly from swine [39] or from pets [40] with close relationships with humans.

\section{Colistin Susceptibility Testing Assays}

For both individual and epidemiological purposes, it is essential to have accurate antimicrobial susceptibility testing (AST) regarding bacteria isolated from infected humans and from animals. 
Because colistin binds to several laboratory materials, many technical issues are raised and the results of colistin susceptibility can be tricky and often incorrect. A survey in 2017, among laboratories providing data, revealed that the majority of the laboratories did not test colistin susceptibility locally or used methods that are not recommended [38].

The Clinical \& Laboratory Standards Institute (CLSI) and the European Committee on Antimicrobial Susceptibility Testing (EUCAST), American and European organizations respectively, responsible for the standardization of AST laboratory protocols, joined efforts to produce colistin susceptibility rules. They have issued recommendations confirming that microdilution is, for the time being, the only susceptibility testing method valid for colistin.

Several difficulties related to the methodology arise in the assessment of susceptibility to colistin. For performing an AST, the 20776-1 standard method of microdilution (BMD) is the reference method and the only one now validated for Enterobacterales, P. aeruginosa, and Acinetobacter spp. Culture media, colistin formulation, and even the kind of plastic used on microplates impact and were standardized. However, such a method is cumbersome and requires a long time to achieve a result (minimum of 24-48 h). Susceptibility testing by other methods, including agar dilution, disk diffusion, gradient diffusion, and automated methods (such as Vitek2, Phoenix), is not recommended, making most of the available epidemiological data not accurate. Newer methods including molecular approaches still need optimization; while they can detect the few, known resistance genes, they cannot formally be considered a susceptibility assay. The detection of resistance genes, such as $m c r$, means that the strain is resistant to colistin, although its absence does not necessarily mean susceptibility. A novel method based upon flow cytometry that allows AST determination in a maximum of $2 \mathrm{~h}$ versus 2 days, directly from positive blood cultures or from colonies ( $2 \mathrm{~h}$ versus 1 day in that case), can change the diagnosis paradigm [41,42]. Quick AST reports by the microbiological lab, in an era of an increase of antimicrobial resistance, are thus urgently needed [43].

\section{Colistin: Human Use}

In recent years, with the scarcity of antimicrobials options available, there is a growing interest in the deprecated antibiotic, the colistin. Colistin has established itself as a last resort therapy in infections of gram-negative multidrug-resistant (MDR) etiology. Because of the nephrotoxicity and neurotoxicity exhibited, colistin was abandoned in the early 1980s, but its resurgence as a resource therapy in critically ill patients is taking place. Regarding its intravenous use, we can identify three milestones in the course of colistin: 1950-1970, for gram-negative infection in general; 1990-2000, in cystic fibrosis with gram-negative MDR infections; and after the passing of the millennium until present time, against infection of gram-negative MDR etiology.

International consensus recommendations for colistin therapy provide a guide for its optimal clinical use [44]. It is often the last line of defense against multidrug-resistant Gram-negative bacteria, namely, Enterobacterales-carbapenemase producers [45,46], Pseudomonas spp., and Acinetobacter spp. Despite being Gram-negative, pathogens such as Brucella sp., Burkholderia cepacia, Helicobacter pylori, Edwarsiella sp., Moraxella catarrhalis, Neisseria sp., Proteus, Providencia, Serratia, and Stenotrophomonas mallei do not generally show susceptibility to colistin and, with regard to Campylobacter sp., its susceptibility has a wide range of variation. However, it is particularly used in critical clinical conditions such as bacteremia or sepsis and pneumonia associated with mechanical ventilation (VAP) in the intensive care unit (ICU). For other several clinical conditions, such as for urinary tract infections, meningitis, osteomyelitis and joint infections, infections of the gastrointestinal tract, pneumonia, abscess, pyoderma and/or soft tissues infections, and eye and ear infections, colistin is seen as an alternative treatment. On the other hand, myasthenia gravis and hypersensitivity to polymyxin are conditions in which the use of colistin is contraindicated and there are no scientific data to support or establish safety in its use in pregnant and lactating women. Colistin should be administered carefully with dose correction accordingly and tight surveillance in patients with renal impairment 
because of its nefrotoxicity. Intravenous polymyxins have been evaluated for the treatment of serious multidrug-resistant P. aeruginosa, Acinetobacter baumannii, and Enterobacterales infections [1].

Intravesical administration of colistin in therapies of persistent urinary tract infections with Acinetobacter baumannii etiology [47] has been described, as well as intrathecal administration in the case of meningitis because of the low permeability to colistin by the hemato-encefalic barrier [48].

Selective decontamination of the digestive tract (SDD) is a practice used in intensive care, in which colistin can be used orally along with a non-prolonged treatment of broad-spectrum parenteral antimicrobials. Despite the existence of scientific data supporting this intensive care practice to reduce bloodstream infections and mortality, when it extends over time, the rising of resistance to colistin among ESBL-producing K. pneumoniae isolates has been seen [49-51]. Recent studies with contradictory conclusions show that this practice is far from the consensus [52,53].

Some authors propose inhaled colistin as monotherapy or associated with systemic therapy in the treatment of pneumonic processes or in chronic pulmonary infection of multi-resistant Gram-negative etiology [54].

Pharmacodynamics (PD) and pharmacokinetics (PK) bring emerging data on colistin as monotherapy. It is very difficult to entrust that monotherapy will produce enoughplasma levels, with the real possibility and danger of promoting the resistance. For this reason, colistin combination therapy seems to increase clinical success and reduce resistance emergence. In vitro experimental data also support the preference for a combination therapy, particularly updated studies through the usage of dynamic models. Several studies, both in vitro and in vivo (mouse model), have pointed out that the association of colistin with other antibiotics, such as rifampicin and imipenem, has a better performance compared with colistin alone in the case of multidrug-resistant Gram-negative bacteria $[55,56]$. However, Lagerbäck et al. recommended that such an approach should be further studied in vivo, considering that colistin combination therapy should be reserved for critical ill patients with multidrug-resistant Gram-negative bacteria pneumonia [56]. This therapeutic approach still needs additional clinical studies, addressing its real effectiveness and, not less important, its resistance potential impact.

Lee et al. conducted a study reporting that the combined therapies with colistin and carbapenem, tigecycline, or rifampicin were more effectively in comparison with the colistin monotherapy treatment regarding positive carbapenemase Klebsiella pneumoniae [57]. The difficulty lies in defining clinical protocols supported by pharmacodynamics and toxicodynamics for combined colistin therapies that allow the highest possible bacterial lethality with the lowest chance of toxicity, and simultaneously prevent the emergence of resistance.

The new cephalosporins associated with beta-lactamases inhibitors like ceftazidime/avibactam could be an alternative for some carbapenemase producing bacteria (especially Enterobacterales KPC and OXA-48), and clinicians are left in a challenging situation: either they keep treating with old well-known drugs or they adopt new antibiotics with insufficient evidence [58].

Regarding Pseudomonas, a synergetic activity of colistin with ceftazidime has been reported as well as the combination of colistin with rifampicin and amikacin. The combination of colistin with rifampicin has also provided a synergetic antibactericidal effect for infections caused by Pseudomonas aeruginosa MDR [1].

Both in vitro and in vivo studies are clear to corroborate that antimicrobial resistance expands when bacterial agents are exposed to inferiorly unsuitable colistin gradients, observed in a significant proportion of patients [59], particularly in isolated heteroresistant strains such as, for example, those of Acinetobacter baumannii [60].

The association with carbapenem, doripenem, or meropenem, as well as with several other antimicrobials, such as rifampicin, glycopeptides, daptomycin, and fusidic acid, generally ineffective in Gram-negatives, revealed a synergistic effect against Acinetobacter baumannii. The effective mechanism of such unlikely combined therapies rests on the polymyxin effect, changing the outer membrane 
permeability, allowing or/and making easier, despite being large molecules, the entry of antimicrobials into the cytoplasm [46].

Discrepancies now can be found on the antimicrobial susceptibility report; recently, CLSI (2000) abolished the classification of susceptible for all gram-negative bacteria Enterobacterales, Pseudomonas, and Acinetobacter, only naming as intermediate or resistant, although EUCAST (2000) still maintains the susceptible category.

Therapeutic drug monitoring of colistin is warranted because its pharmacokinetics is quite variable and because its therapeutic window is narrow [61]. This aspect makes the management of the colistin treatment challenging, stressing the need for the availability of practical and simple methods with a short response time, including a drug monitoring assay.

\section{Colistin: Veterinary Use and Its Impact}

At present, colistin is an antibiotic still widely used in veterinary medicine, mostly in pigs, for the oral treatment of intestinal infections caused by Enterobacterales [62]. The administration of antibiotics like colistin in animals supported the growing of modern farm animal productions, allowing successful weaning, higher animal density, and probably higher viability of economic control of pathologies caused by E. coli infections such as that caused by verotoxigenic E. coli (VTEC) [22]. Colistin is poorly absorbed through the gastrointestinal tract. This fact stresses the emergence of colistin resistance as a result of selective pressure upon the intestinal microbiota [22]. Pigs treated with colistin had overall higher proportions of resistant isolates compared with pigs not treated [62]. Colistin is also used orally in calves for the treatment of gastrointestinal diseases caused by Gram-negative bacteria. This use may also explain the isolation of colistin-resistant bacteria from calves, despite the lack of solid data about the treatment of these animals with colistin [32].

Notably, the most common use of colistin in swine industrial production worldwide is the oral route and for prophylatic purposes [63]. Colistin was mainly administered via feed, but also through drinking water [64]. This practice involves medicating all animals in the same farm, resulting in treating animals with clinical symptoms together with healthy ones. The European Medicines Agency (EMA) made a categorization for colistin use, which was reviewed in 2016 [64]. Colistin therapies with prophylactic purposes carry a high risk in the emergence of resistance, and thus should be banned. Its clinical use should be limited to enteric infections caused by susceptible non-invasive E. coli and supported by an AST whenever possible [43,64].

Although colistin, in oral treatment, is generally used as monotherapy [22], there are some pharmaceutical forms on the market with colistin, under the sulfate salt chemical form, that allow combined therapy. The most common association with other antimicrobials is with $\beta$-lactamics and mainly amoxicillin [65]. In vitro data show the combination of amoxicillin with colistin reveals a synergistic or additive effect against pathogenic E. coli of avian source [66]. Combinations of colistin and amoxicillin plus zinc oxide $(\mathrm{ZnO})$ during the pre-weaning and weaning periods incorporated in the swine feed were also used [67]. A study carried out in fecal samples of weaned piglets showed that the combination of three antimicrobials, colistin, bacitracin-zinc, and chlortetracycline, inhibits the rise in tet resistance genes (tet $X$, tet $C$, tet $L$, and tetW) [68]. Despite the suppression in tet resistance genes, no data exist regarding resistance to colistin after using this combined therapy. Because of a lack of evidence, the combined therapy cannot be scientifically sustained, particularly among pigs. Considering all the available updated knowledge, the Committee for Medicinal Products for Veterinary Use (CVMP), basing the decision on the precautionary principle, recommended the Market Authorization withdrawal for all Market Authorization Holders and all veterinary pharmaceutical formulas associating colistin and other antibiotics [64].

The use of colistin as a growth promoter of farm animals, still adopted specially in Asia, should be banned. Low sub-inhibitory concentrations of antibiotics used to improve animal growth have been linked to the emergence of antibiotic resistance [22]. Notably, antimicrobials for animal growth promotion can generally be purchased without veterinary control even in the European Union. 
High sanitation, by controlling the microbial burden in the farm, is a key factor to help to ban antimicrobial misuse.

As a general attitude with all antimicrobials, but in particular with colistin, the veterinary surgeon should ensure that the antimicrobial prescribed is applied strictly for the treatment of sick animals as recommended in compliance with label instructions. Any deviations from the EMA guidelines should be justified and recorded [11,64]. In this context, extra-label use of colistin such as, for example, in countries where this antibiotic is not approved in swine, must take place within a valid veterinary justification relying upon AST reports and without the availability of other therapeutic alternatives.

Further research is mandatory in order to determine the withdrawal period allowing the risk reduction of animals sent to slaughter harboring colistin resistant bacteria carrying mor genes.

Animal-to-human transmission of $m c r-1$ resistance raises issues concerning the consequences of using colistin in veterinary medicine (in pet treatment, farm animal's production, and its penetration in the consumption food chain) in terms of human health [39]. mor-1 might be present in the environment and transmissible by several routes to humans. Therefore, it could also add to the potential transferring of the $m c r-1$ gene from animal to human. Such transfer routes require additional and more comprehensive studies.

The veterinary surgeon should seek that colistin use only targets clinical disease and consider banning its use whenever feasible. Educational and awareness campaigns for pig farmers and employees are essential. Records detailing colistin use in animals are equally critical as they provide support to allow the development of policies and guidelines and to assess the effect of possible interventions. It has been shown that colistin-resistant $E$. coli was isolated from healthy individuals without prior medical colistin use [69].

Additionally, reports from Italy, the second country using colistin adjusted for biomass under exposure in European Union [64], describe the detection of colistin-resistant E. coli from wild rabbits (Oryctolagus cuniculus) and wild hares (Lepus europaeus) that were not previously treated with colistin [70]. Consequently, wildlife may also play a role in colistin resistance, being a potential reservoir in the environment, and contribute to its transmission to other animals and/or humans through contaminated food and water or by direct human and animal contact.

Apart from the previous isolation of bacteria resistant to colistin from manure, water, migratory birds, and vegetables $[23,71-73]$, the ecotoxicity of this antimicrobial and its impact is an issue to take into consideration $[74,75]$. The colistin, at high levels, present in swine farms' wastewater, is related to the toxicity exhibited in the bacteria responsible for oxidizing ammonia [74]. The biotransformation of xenobiotic substances along with the chemical transformation of ammonia into nitrites in wastewater treatment plants is ensured by these bacteria responsible for the oxidation of ammonia [74]. The significant damage inflicted on the intestinal epithelium and the greater expression of stress-related genes in the earthworm Eisenia fetida are other rising ecotoxic markers revealing the environmental toxicity caused by the elimination of colistin in wastewater [75].

It should be remembered that administered antibiotics are not $100 \%$ metabolized by animals or humans; many are excreted in an active form via the feces or urine. This fact is even more marked with oral administration of colistin, which is very poorly absorbed by the gastrointestinal tract [22].

Composting methods have been reported to be able to eliminate on average $50-70 \%$ of some antimicrobials, such as chlortetracycline, monensin, and tylosin [76], also helping to reduce the relative amounts of the $b l a_{\mathrm{TEM}}, s u l 3$, and $\operatorname{erm}(\mathrm{B})$ genes in manure [77]. Unfortunately, they do not work in reducing the amounts of colistin or $m c r$ genes in pig manure. The method in which manure is handled or treated has a variable impact on the effectiveness of reducing antibiotic resistance genes (ARGs) in pig manure; that is, aerobic biofiltration of manure seems to be more effective to reduce erm $(\mathrm{X})$ than other ARGs such as erm(F), erm (B), and tet (G), while mesophilic anaerobic digestion and lagoon storage reduced none of these ARGs [78]. A great deal of controversy still involves the effectiveness of these biological treatments of manure, such as lagoons and composting, in ARG reduction [76]. To ensure the destruction of resistant bacteria and ARGs present in animal and human waste is mandatory in further 
research. It is necessary to ensure the effectiveness of waste treatment processes, particularly with regard to pig manure. The agricultural role of swine manure in soil fertilization and the absence of regulations and guidelines should be considered to control and monitor the use of swine manure [22].

\section{Conclusions}

An interdisciplinary collaboration and communication between all the specialists involved is necessary to develop a universal strategy that fosters the reduction of the emergence of resistance to colistin in human, veterinary medicine, and the environment. The scientific community, experts, and government authorities urge for a reduction of colistin usage, recommending its prescription only for the treatment of infections as a last resource under strict circumstances. Colistin use should involve a scientific evaluation of the effectiveness of other drugs and implement alternative strategies against infections caused by Enterobacterales whenever possible, avoiding antimicrobials at all, particularly in preventive strategies. The mcr-1 gene was isolated on four continents and, most worrying, from sources other than food animals, such as the environment as well as from human isolates. In addition, some E. coli isolates harboring the plasmid-encoded mor genes, now known up to mcr-9, were also ESBL or carbapenemase enzyme producers. All such facts cause great concern about the eventual loss of colistin effectiveness regarding the treatment of multidrug-resistant Gram-negative bacilli in humans. Epidemiological data could not be accurate owing to technical issues involved in the susceptibility evaluation. Rapid and accurate ASTs are urgently needed. This highlights the need for the judicious use of colistin in order to avoid the development of pan-resistant strains that are not bound by land borders and do not require a passport or visa.

Funding: This article was supported by National Funds through FCT—Fundação para a Ciência e a Tecnologia, I.P., within CINTESIS, R\&D Unit (reference UIDB/4255/2020).

Conflicts of Interest: The authors declare no conflict of interest. The funders had no role in the design of the study; in the collection, analyses, or interpretation of data; in the writing of the manuscript, or in the decision to publish the results.

\section{References}

1. Falagas, M.E.; Kasiakou, S.K. Colistin: The revival of polymyxins for the management of multidrug-resistant gram-negative bacterial infections. Clin. Infect. Dis. 2005, 40, 1333-1341. [CrossRef]

2. Gallardo-Godoy, A.; Muldoon, C.; Becker, B.; Elliott, A.G.; Lash, L.H.; Huang, J.X.; Butler, M.S.; Pelingon, R.; Kavanagh, A.M.; Ramu, S.; et al. Activity and Predicted Nephrotoxicity of Synthetic Antibiotics Based on Polymyxin B. J. Med. Chem. 2016, 59, 1068-1077. [CrossRef]

3. Cassir, N.; Rolain, J.M.; Brouqui, P. A new strategy to fight antimicrobial resistance: The revival of old antibiotics. Front. Microbiol. 2014, 5, 551. [CrossRef]

4. Brink, A.J.; Richards, G.A.; Colombo, G.; Bortolotti, F.; Colombo, P.; Jehl, F. Multicomponent antibiotic substances produced by fermentation: Implications for regulatory authorities, critically ill patients and generics. Int. J. Antimicrob. Agents 2014, 43, 1-6. [CrossRef]

5. Falagas, M.E.; Rafailidis, P.I. Re-emergence of colistin in today's world of multidrug-resistant organisms: Personal perspectives. Expert Opin. Investig. Drugs 2008, 17, 973-981. [CrossRef]

6. Velkov, T.; Thompson, P.E.; Nation, R.L.; Li, J. Structure-activity relationships of polymyxin antibiotics. J. Med. Chem. 2010, 53, 1898-1916. [CrossRef]

7. Biswas, S.; Brunel, J.M.; Dubus, J.C.; Reynaud-Gaubert, M.; Rolain, J.M. Colistin: An update on the antibiotic of the 21st century. Expert Rev. Anti Infect. Ther. 2012, 10, 917-934. [CrossRef]

8. Azzopardi, E.A.; Boyce, D.E.; Thomas, D.W.; Dickson, W.A. Colistin in burn intensive care: Back to the future? Burns 2013, 39, 7-15. [CrossRef]

9. WHO. Critically Important Antimicrobials for Human Medicine; WHO: Geneva, Switzerland, 2018. Available online: https://apps.who.int/iris/bitstream/handle/10665/312266/9789241515528-eng.pdf (accessed on 7 February 2020). 
10. Government of Canada. Canadian Integrated Program for Antimicrobial Resistance Surveillance (CIPARS) 2012 Annual Report-Chapter 1 Design and Methods; Public Health Agency of Canada, Government of Canada: Guelph, ON, Canada, 2014. Available online: http://publications.gc.ca/collections/collection_2014/aspc-phac/ HP2-4-2012-1-eng.pdf (accessed on 7 February 2020).

11. European Medicines Agency. Categorisation of Antibiotics in the European Union. Answer to the Request from the European Commission for Updating the Scientific Advice on the Impact on Public Health and Animal Health of the Use of Antibiotics in Animals. 2019. Available online: https://www.ema.europa.eu/en/documents/report/ categorisation-antibiotics-european-union-answer-request-european-commission-updating-scientific_en. pdf (accessed on 7 February 2020).

12. Deris, Z.Z.; Akter, J.; Sivanesan, S.; Roberts, K.D.; Thompson, P.E.; Nation, R.L.; Li, J.; Velkov, T. A secondary mode of action of polymyxins against Gram-negative bacteria involves the inhibition of NADH-quinone oxidoreductase activity. J. Antibiot. 2014, 67, 147-151. [CrossRef]

13. Bolla, J.M.; Alibert-Franco, S.; Handzlik, J.; Chevalier, J.; Mahamoud, A.; Boyer, G.; Kieć-Kononowicz, K.; Pags, J.M. Strategies for bypassing the membrane barrier in multidrug resistant Gram-negative bacteria. FEBS Lett. 2011, 585, 1682-1690. [CrossRef]

14. Needham, B.D.; Trent, M.S. Fortifying the barrier: The impact of lipid A remodelling on bacterial pathogenesis. Nat. Rev. Microbiol. 2013, 11, 467-481. [CrossRef]

15. Falagas, M.E.; Rafailidis, P.I.; Matthaiou, D.K. Resistance to polymyxins: Mechanisms, frequency and treatment options. Drug Resist. Updates 2010, 13, 132-138. [CrossRef]

16. Olaitan, A.O.; Morand, S.; Rolain, J.M. Mechanisms of polymyxin resistance: Acquired and intrinsic resistance in bacteria. Front. Microbiol. 2014, 5, 643. [CrossRef]

17. Ly, N.S.; Yang, J.; Bulitta, J.B.; Tsuji, B.T. Impact of two-component regulatory systems PhoP-PhoQ and PmrA-PmrB on colistin pharmacodynamics in Pseudomonas aeruginosa. Antimicrob. Agents Chemother. 2012, 56, 3453-3456. [CrossRef]

18. Moffatt, J.H.; Harper, M.; Harrison, P.; Hale, J.D.F.; Vinogradov, E.; Seemann, T.; Henry, R.; Crane, B.; Michael, F.S.; Cox, A.D.; et al. Colistin resistance in Acinetobacter baumannii is mediated by complete loss of lipopolysaccharide production. Antimicrob. Agents Chemother. 2010, 54, 4971-4977. [CrossRef] [PubMed]

19. López-Camacho, E.; Gómez-Gil, R.; Tobes, R.; Manrique, M.; Lorenzo, M.; Galván, B.; Salvarelli, E.; Moatassim, Y.; Salanueva, I.J.; Pareja, E.; et al. Genomic analysis of the emergence and evolution of multidrug resistance during a klebsiella pneumoniae outbreak including carbapenem and colistin resistance. J. Antimicrob. Chemother. 2014, 69, 632-636. [CrossRef]

20. Poirel, L.; Jayol, A.; Bontron, S.; Villegas, M.V.; Ozdamar, M.; Türkoglu, S.; Nordmann, P. The mgrB gene as a key target for acquired resistance to colistin in Klebsiella pneumoniae. J. Antimicrob. Chemother. 2015, 70, 75-80. [CrossRef]

21. Liu, Y.Y.; Wang, Y.; Walsh, T.R.; Yi, L.X.; Zhang, R.; Spencer, J.; Doi, Y.; Tian, G.; Dong, B.; Huang, X.; et al. Emergence of plasmid-mediated colistin resistance mechanism MCR-1 in animals and human beings in China: A microbiological and molecular biological study. Lancet Infect. Dis. 2016, 16, 161-168. [CrossRef]

22. Rhouma, M.; Beaudry, F.; Letellier, A. Resistance to colistin: What is the fate for this antibiotic in pig production? Int. J. Antimicrob. Agents 2016, 48, 119-126. [CrossRef]

23. Schwarz, S.; Johnson, A.P. Transferable resistance to colistin: A new but old threat. J. Antimicrob. Chemother. 2016, 71, 2066-2070. [CrossRef]

24. Skov, R.L.; Monnet, D.L. Plasmid-mediated colistin resistance (mcr-1 gene): Three months later, the story unfolds. Eurosurveillance 2016, 21, 30155. [CrossRef] [PubMed]

25. Giamarellou, H. Epidemiology of infections caused by polymyxin-resistant pathogens. Int. J. Antimicrob. Agents 2016, 48, 614-621. [CrossRef]

26. Veldman, K.; van Essen-Zandbergen, A.; Rapallini, M.; Wit, B.; Heymans, R.; van Pelt, W.; Mevius, D. Location of colistin resistance gene mcr-1 in Enterobacteriaceae from livestock and meat. J. Antimicrob. Chemother. 2016, 71, 2340-2342. [CrossRef] [PubMed]

27. Xavier, B.B.; Lammens, C.; Ruhal, R.; Malhotra-Kumar, S.; Butaye, P.; Goossens, H.; Malhotra-Kumar, S. Identification of a novel plasmid-mediated colistinresistance gene, mcr-2, in Escherichia coli, Belgium, June 2016. Eurosurveillance 2016, 21, 30280. [CrossRef] [PubMed]

28. Quesada, A.; Ugarte-Ruiz, M.; Iglesias, M.R.; Porrero, M.C.; Martínez, R.; Florez-Cuadrado, D.; Campos, M.J.; García, M.; Píriz, S.; Sáez, J.L.; et al. Detection of plasmid mediated colistin resistance (MCR-1) in Escherichia 
coli and Salmonella enterica isolated from poultry and swine in Spain. Res. Vet. Sci. 2016, 105, 134-135. [CrossRef]

29. Anjum, M.F.; Duggett, N.A.; AbuOun, M.; Randall, L.; Nunez-Garcia, J.; Ellis, R.J.; Rogers, J.; Horton, R.; Brena, C.; Williamson, S.; et al. Colistin resistance in Salmonella and Escherichia coli isolates from a pig farm in Great Britain. J. Antimicrob. Chemother. 2016, 71, 2306-2313. [CrossRef]

30. Malhotra-Kumar, S.; Xavier, B.B.; Das, A.J.; Lammens, C.; Hoang, H.T.T.; Pham, N.T.; Goossens, H. Colistin-resistant Escherichia coli harbouring mcr-1 isolated from food animals in Hanoi, Vietnam. Lancet Infect. Dis. 2016, 16, 286-287. [CrossRef]

31. Falgenhauer, L.; Waezsada, S.E.; Yao, Y.; Imirzalioglu, C.; Käsbohrer, A.; Roesler, U.; Michael, G.B.; Schwarz, S.; Werner, G.; Kreienbrock, L.; et al. Colistin resistance gene mcr-1 in extended-spectrum $\beta$-lactamase-producing and carbapenemase-producing Gram-negative bacteria in Germany. Lancet Infect. Dis. 2016, 16, 282-283. [CrossRef]

32. Haenni, M.; Poirel, L.; Kieffer, N.; Châtre, P.; Saras, E.; Métayer, V.; Dumoulin, R.; Nordmann, P.; Madec, J.Y. Co-occurrence of extended spectrum $\beta$ lactamase and MCR-1 encoding genes on plasmids. Lancet Infect. Dis. 2016, 16, 281-282. [CrossRef]

33. Poirel, L.; Kieffer, N.; Liassine, N.; Thanh, D.; Nordmann, P. Plasmid-mediated carbapenem and colistin resistance in a clinical isolate of Escherichia coli. Lancet Infect. Dis. 2016, 16, 281. [CrossRef]

34. Yang, Y.Q.; Li, Y.X.; Lei, C.W.; Zhang, A.Y.; Wang, H.N. Novel plasmid-mediated colistin resistance gene mcr-7.1 in Klebsiella pneumoniae. J. Antimicrob. Chemother. 2018, 73, 1791-1795. [CrossRef]

35. Carroll, L.M.; Gaballa, A.; Guldimann, C.; Sullivan, G.; Henderson, L.O.; Wiedmann, M. Identification of novel mobilized colistin resistance gene mcr-9 in a multidrug-resistant, colistin-susceptible Salmonella enterica serotype typhimurium isolate. MBio 2019, 10, e00853-19. [CrossRef]

36. Rebelo, A.R.; Bortolaia, V.; Kjeldgaard, J.S.; Pedersen, S.K.; Leekitcharoenphon, P.; Hansen, I.M.; Guerra, B.; Malorny, B.; Borowiak, M.; Hammerl, J.A.; et al. Multiplex PCR for detection of plasmid-mediated colistin resistance determinants, mcr-1, mcr-2, mcr-3, mcr-4 and mcr-5 for surveillance purposes. Eurosurveillance 2018, 23, 17-00672. [CrossRef]

37. European Centre for Disease Prevention and Control. Antimicrobial Resistance Surveillance in Europe 2016; Annual Report of the European Antimicrobial Resistance Surveillance Network (EARS-Net); European Centre for Disease Prevention and Control: Solna, Sweden, 2017. [CrossRef]

38. European Centre for Disease Prevention and Control. Surveillance of antimicrobial resistance in Europe Annual report of the European Antimicrobial Resistance Surveillance Network (EARS-Net) 2017. In ECDC: Surveillance Report; European Centre for Disease Prevention and Control: Solna, Sweden, 2018. [CrossRef]

39. Olaitan, A.O.; Thongmalayvong, B.; Akkhavong, K.; Somphavong, S.; Paboriboune, P.; Khounsy, S.; Morand, S.; Rolain, J.M. Clonal transmission of a colistin-resistant Escherichia coli from a domesticated pig to a human in Laos. J. Antimicrob. Chemother. 2015, 70, 3402-3404. [CrossRef] [PubMed]

40. Zhang, X.F.; Doi, Y.; Huang, X.; Li, H.Y.; Zhong, L.L.; Zeng, K.J.; Zhang, Y.F.; Patil, S.; Tian, G.B. Possible transmission of mcr-1-harboring escherichia coli between companion animals and human. Emerg. Infect. Dis. 2016, 22, 167. [CrossRef]

41. Fonseca e Silva, D.; Silva-Dias, A.; Gomes, R.; Martins-Oliveira, I.; Ramos, M.H.; Rodrigues, A.G.; Cantón, R.; Pina-Vaz, C. Evaluation of rapid colistin susceptibility directly from positive blood cultures using a flow cytometry assay. Int. J. Antimicrob. Agents 2019, 54, 820-823. [CrossRef]

42. Van Belkum, A.; Burnham, C.A.D.; Rossen, J.W.A.; Mallard, F.; Rochas, O.; Dunne, W.M. Innovative and rapid antimicrobial susceptibility testing systems. Nat. Rev. Microbiol. 2020, 18, 299-311. [CrossRef] [PubMed]

43. Andrade, F.F.; Pina-Vaz, C.; Rodrigues, A.G. Antimicrobial Resistance: A One Health Concept Perspective Analysis. Infect. Dis. Diagn. Treat. 2018, 1, 1-9. [CrossRef]

44. Tsuji, B.T.; Pogue, J.M.; Zavascki, A.P.; Paul, M.; Daikos, G.L.; Forrest, A.; Giacobbe, D.R.; Viscoli, C.; Giamarellou, H.; Karaiskos, I.; et al. International Consensus Guidelines for the Optimal Use of the Polymyxins: Endorsed by the American College of Clinical Pharmacy (ACCP), European Society of Clinical Microbiology and Infectious Diseases (ESCMID), Infectious Diseases Society of America (IDSA), International Society for Anti-infective Pharmacology (ISAP), Society of Critical Care Medicine (SCCM), and Society of Infectious Diseases Pharmacists (SIDP). Pharmacotherapy 2019, 39, 10-39. [CrossRef] [PubMed]

45. Gurjar, M. Colistin for lung infection: An update. J. Intensive Care 2015, 3, 3. [CrossRef] 
46. Bergen, P.J.; Bulman, Z.P.; Landersdorfer, C.B.; Smith, N.; Lenhard, J.R.; Bulitta, J.B.; Nation, R.L.; Li, J.; Tsuji, B.T. Optimizing Polymyxin Combinations Against Resistant Gram-Negative Bacteria. Infect. Dis. Ther. 2015, 4, 391-415. [CrossRef] [PubMed]

47. Volkow-Fernández, P.; Rodríguez, C.F.; Cornejo-Juárez, P. Intravesical colistin irrigation to treat multidrug-resistant Acinetobacter baumannii urinary tract infection: A case report. J. Med. Case Rep. 2012, 6, 426. [CrossRef] [PubMed]

48. Michalopoulos, A.; Falagas, M.E. Colistin and Polymyxin B in Critical Care. Crit. Care Clin. 2008, $24,377-391$. [CrossRef] [PubMed]

49. De Jonge, E.; Schultz, M.J.; Spanjaard, L.; Bossuyt, P.M.M.; Vroom, M.B.; Dankert, J.; Kesecioglu, J. Effects of selective decontamination of digestive tract on mortality and acquisition of resistant bacteria in intensive care: A randomised controlled trial. Lancet 2003, 362, 1011-1016. [CrossRef]

50. Silvestri, L.; van Saene, H.K.F.; Milanese, M.; Gregori, D.; Gullo, A. Selective decontamination of the digestive tract reduces bacterial bloodstream infection and mortality in critically ill patients. Systematic review of randomized, controlled trials. J. Hosp. Infect. 2007, 65, 187-203. [CrossRef]

51. Halaby, T.; Naiemi, N.; Al Kluytmans, J.; Van Der Palen, J.; Vandenbroucke-Grauls, C.M.J.E. Emergence of colistin resistance in Enterobacteriaceae after the introduction of selective digestive tract decontamination in an intensive care unit. Antimicrob. Agents Chemother. 2013, 57, 3224-3229. [CrossRef]

52. Hurley, J.C. Selective Digestive Decontamination Is Neither Safe Nor Efficacious for Critically Ill Patients. Crit. Care Med. 2020, 48, 732-735. [CrossRef]

53. Bonten, M.J. Selective Decontamination Is Safe and Efficacious for Critically Ill Patients. Crit. Care Med. 2020, 48, 736-738. [CrossRef]

54. Lu, Q.; Luo, R.; Bodin, L.; Yang, J.; Zahr, N.; Aubry, A.; Golmard, J.L.; Rouby, J.J. Efficacy of high-dose nebulized colistin in ventilator-associated pneumonia caused by multidrug-resistant pseudomonas aeruginosa and acinetobacter baumannii. Anesthesiology 2012, 117, 1335-1347. [CrossRef]

55. Årdal, C.; Outterson, K.; Hoffman, S.J.; Ghafur, A.; Sharland, M.; Ranganathan, N.; Smith, R.; Zorzet, A.; Cohn, J.; Pittet, D.; et al. International cooperation to improve access to and sustain effectiveness of antimicrobials. Lancet 2016, 387, 296-307. [CrossRef]

56. Lagerbäck, P.; Khine, W.W.T.; Giske, C.G.; Tängdén, T. Evaluation of antibacterial activities of colistin, rifampicin and meropenem combinations against NDM-1-producing Klebsiella pneumoniae in $24 \mathrm{~h}$ in vitro time-kill experiments. J. Antimicrob. Chemother. 2016, 71, 2321-2325. [CrossRef] [PubMed]

57. Lee, G.C.; Burgess, D.S. Treatment of Klebsiella Pneumoniae Carbapenemase (KPC) infections: A review of published case series and case reports. Ann. Clin. Microbiol. Antimicrob. 2012, 11, 32. [CrossRef]

58. Durante-Mangoni, E.; Andini, R.; Zampino, R. Management of carbapenem-resistant Enterobacteriaceae infections. Clin. Microbiol. Infect. 2019, 25, e943-e950. [CrossRef]

59. Garonzik, S.M.; Li, J.; Thamlikitkul, V.; Paterson, D.L.; Shoham, S.; Jacob, J.; Silveira, F.P.; Forrest, A.; Nation, R.L. Population pharmacokinetics of colistin methanesulfonate and formed colistin in critically ill patients from a multicenter study provide dosing suggestions for various categories of patients. Antimicrob. Agents Chemother. 2011, 55, 3284-3294. [CrossRef] [PubMed]

60. Tsuji, B.T.; Landersdorfer, C.B.; Lenhard, J.R.; Cheah, S.E.; Thamlikitkul, V.; Rao, G.G.; Holden, P.N.; Forrest, A.; Bulitta, J.B.; Nation, R.L.; et al. Paradoxical effect of polymyxin B: High drug exposure amplifies resistance in Acinetobacter baumannii. Antimicrob. Agents Chemother. 2016, 60, 3913-3920. [CrossRef] [PubMed]

61. Grégoire, N.; Aranzana-Climent, V.; Magréault, S.; Marchand, S.; Couet, W. Clinical Pharmacokinetics and Pharmacodynamics of Colistin. Clin. Pharmacokinet. 2017, 56, 1441-1460. [CrossRef]

62. Burow, E.; Rostalski, A.; Harlizius, J.; Gangl, A.; Simoneit, C.; Grobbel, M.; Kollas, C.; Tenhagen, B.A.; Käsbohrer, A. Antibiotic resistance in Escherichia coli from pigs from birth to slaughter and its association with antibiotic treatment. Prev. Vet. Med. 2019, 165, 52-62. [CrossRef]

63. Trauffler, M.; Griesbacher, A.; Fuchs, K.; Köfer, J. Antimicrobial drug use in Austrian pig farms: Plausibility check of electronic on-farm records and estimation of consumption. Vet. Rec. 2014, 175, 402. [CrossRef] [PubMed]

64. European Medicines Agency. Updated Advice on the Use of Colistin Products in Animals within the European Union: Development of Resistance and Possible Impact on Human and Animal Health (EMA/CVMP/CHMP/231573/2016). 2016. Available online: https://www.ema.europa.eu/en/documents/ 
scientific-guideline/updated-advice-use-colistin-products-animals-within-european-union-developmentresistance-possible_en-0.pdf (accessed on 7 February 2020).

65. He, J.; Tang, S.; Li, L.; Zhang, C.; Li, X.; Xia, X.; Xiao, X. Pharmacokinetics of a novel amoxicillin/colistin suspension after intramuscular administration in pigs. J. Vet. Pharmacol. Ther. 2011, 34, 42-50. [CrossRef]

66. Hamouda, A.; Elbanna, H.; Haddad, M.; Aggarwal, T.; Khatri, A.; Siddiqui, S.S. Combined antimicrobial effect against some isolated bacteria from chickens. J. Physiol. Pharmacol. Adv. 2011, 1, 1-25.

67. Moreno, M.A. Survey of quantitative antimicrobial consumption per production stage in farrow-to-finish pig farms in Spain. Vet. Record Open 2014, 1, e000002. [CrossRef] [PubMed]

68. Li, H.; Chu, Q.; Xu, F.; Fu, L.; Liang, T.; Li, Y.; Zhou, B. Combination of antibiotics suppressed the increase of a part of ARGs in fecal microorganism of weaned pigs. Environ. Sci. Pollut. Res. 2016. [CrossRef] [PubMed]

69. Olaitan, A.O.; Morand, S.; Rolain, J.M. Emergence of colistin-resistant bacteria in humans without colistin usage: A new worry and cause for vigilance. Int. J. Antimicrob. Agents 2016, 47, 1-3. [CrossRef] [PubMed]

70. Dotto, G.; Giacomelli, M.; Grilli, G.; Ferrazzi, V.; Carattoli, A.; Fortini, D.; Piccirillo, A. High prevalence of oqxAB in Escherichia coli isolates from domestic and wild lagomorphs in Italy. Microb. Drug Resist. 2014, 20 , 118-123. [CrossRef]

71. Petrillo, M.; Angers-Loustau, A.; Kreysa, J. Possible genetic events producing colistin resistance gene mcr-1. Lancet Infect. Dis. 2016, 16, 280. [CrossRef]

72. Ruzauskas, M.; Vaskeviciute, L. Detection of the mcr-1 gene in Escherichia coli prevalent in the migratory bird species Larus argentatus. J. Antimicrob. Chemother. 2016, 71, 2333-2334. [CrossRef]

73. Zurfuh, K.; Poirel, L.; Nordmann, P.; Nüesch-Inderbinen, M.; Hächler, H.; Stephan, R. Occurrence of the Plasmid-Borne mcr-1 Colistin Resistance Gene in Extended-Spectrum-Lactamase-Producing Enterobacteriaceae in River Water and Imported Vegetable Samples in Switzerland. Antimicrob. Agents Chemother. 2016, 60, 2594-2595. [CrossRef]

74. Bressan, C.R.; Kunz, A.; Schmidell, W.; Soares, H.M. Toxicity of the colistin sulfate antibiotic used in animal farming to mixed cultures of nitrifying organisms. Water Air Soil Pollut. 2013, 224, 1441. [CrossRef]

75. Guo, R.; Ding, X.; Zhong, X.; Gao, S.; Sun, Y. Molecular and ultrastructural insights into the earthworm Eisenia fetida of the assessment of ecotoxicity during colistin exposure. Environ. Sci. Pollut. Res. 2014, 21, 13405-13411. [CrossRef]

76. Pruden, A.; Joakim Larsson, D.G.; Amézquita, A.; Collignon, P.; Brandt, K.K.; Graham, D.W.; Lazorchak, J.M.; Suzuki, S.; Silley, P.; Snape, J.R.; et al. Management options for reducing the release of antibiotics and antibiotic resistance genes to the environment. Environ. Health Perspect. 2013, 121, 878-885. [CrossRef]

77. Le Devendec, L.; Mourand, G.; Bougeard, S.; Léaustic, J.; Jouy, E.; Keita, A.; Couet, W.; Rousset, N.; Kempf, I. Impact of colistin sulfate treatment of broilers on the presence of resistant bacteria and resistance genes in stored or composted manure. Vet. Microbiol. 2016, 194, 98-106. [CrossRef]

78. Chen, J.; Michel, F.C.; Sreevatsan, S.; Morrison, M.; Yu, Z. Occurrence and Persistence of Erythromycin Resistance Genes (erm) and Tetracycline Resistance Genes (tet) in Waste Treatment Systems on Swine Farms. Microb. Ecol. 2010, 60, 479-486. [CrossRef] [PubMed]

Publisher's Note: MDPI stays neutral with regard to jurisdictional claims in published maps and institutional affiliations.

(C) 2020 by the authors. Licensee MDPI, Basel, Switzerland. This article is an open access article distributed under the terms and conditions of the Creative Commons Attribution (CC BY) license (http://creativecommons.org/licenses/by/4.0/). 